\title{
A Glimpse on Silver Nanoparticles Genotoxicity in Higher Plants
}

\author{
Saha $\mathrm{N}^{*}$ and Gupta SD \\ Department of Agricultural and Food Engineering, Indian Institute of Technology, India
}

Submission: March 30, 2017; Published: May 04, 2017

*Corresponding author: Nirlipta Saha, Department of Agricultural and Food Engineering, Indian Institute of Technology, India, Tel: +919434495050; E-mail: nirlipta@agfe.iitkgp.ernet.in

Abstract

Nanoparticle induced toxicity is influenced by several parameters like nanoparticle size, shape, coating, use of carrier, genotypes and experimental methods. Recent reports indicated that many metallic nanomaterials especially silver (AgNPs) cause significant toxic effects in animal cell culture and animal models, however, phytotoxicity studies are still limited. This mini review analyzed recent progress in the understanding of the impact of AgNPs on plant species. Among different studies related to oxidative stress-related gene expression, genotoxicity, seed germination, and root elongation, genotoxic effect of AgNPs have attained considerable attention in recent years. Genotoxicity studies revealed different types of chromosomal abnormalities and DNA damages which ultimately leads to cell death and disintegration of plants cell exposed to different coated and uncoated AgNPs present in the environment.

\section{Introduction}

Particles with sizes between 1 and $100 \mathrm{~nm}$ are termed as nanoparticles and are used commercially across several industrial processes. Since last four decades, different varieties of nanostructures are produced and among them the market potential of AgNPs is predicted to rise from recent 0.79 billion to $\$ 2.54$ billion by 2022 [1]. Different mode of applications of AgNPs makes them bioavailable in the environment. Soil environment are polluted by means of land application for biosolids wastewater treatment, accidental spills, applications of agrochemicals (e.g., nano-pesticides, fertilizers, and herbicides), washing and aging silver-containing products [2-4]. Higher exposure of AgNPs to different plants leads to penetration of the nanoparticles into the plants cells. The interference of AgNPs during DNA repair was the most detrimental one which finally leads to blockage of synthesis of DNA. Depolymerization of spindle fibers, partial suppression of spindle fiber formation, interruption in mitotic fuse and inappropriate segregation of daughter cells occurs in different plant cells exposed to AgNPs. Thus the present review summarizes the genotoxic effect of AgNPs on higher plants.

\section{Discussion}

Internalization of AgNps when treated on Allium cepa roots lead to DNA damage and different chromosomal aberrations [5].
Decrease in the mean mitotic index values in silver nanoparticle exposed root-tips were observed in Viciafaba plants [6]. Similar results were observed with aluminum oxide and chromium oxide nanoparticles [7,8]. Reports available till date indicated that most of the nanotoxicity studies focused on chemically synthesized AgNPs against plant systems [5,6,9], microbial communities [10] and animal cell lines [11]. Very few reports emphasized on the effect of biologically synthesized nanoparticles. Low dose toxicity of biologically synthesized AgNP was reported on Allium cepa plant species [4]. These AgNPs cause severe mitotic and meiotic abnormalities in the root tips and flower bud cells of plant Alium cepa. With increasing concentration of nanoparticles the severity of chromosomal aberrations increased. Mitotic and meiotic indices of the treated cells also decreased with the increase in intensity of the treatments.

Different types of mitotic chromosomal aberrations observed in different toxicity studies were clumped chromosome, C-metaphase, disturbed metaphase chromosomes, differential condensation and segregation of chromosome, diagonal anaphase, single and multiple bridge formation with fragmentation, anaphase chromosome protruded out, multi polar anaphase, sticky anaphase, chromosome split, sticky metaphase with ring formation and nuclear migration $[4,5]$. On the other hand meiotic studies revealed abnormalities like metaphase chromosome fragmentation, undifferentiated bivalents, 
out-of plate bivalents, differential metaphase chromosome condensation and formation of segregated chromosome, precocious movement of chromosome at metaphase, sticky metaphase, multi polar anaphase, anaphase laggard, and diagonal anaphase. In the tetrad phase aberrations like dyad with formation of micronuclei, triad formation, and tetrad with connected chromosome were noted [4].

\section{Conclusion}

Regulation of release of AgNPs into the environment after its use in different nano-based industries requires much attention. The genotoxic effects observed are highly detrimental to the overall health status of higher plants. AgNPs impose a variety of genetic, cytological, metabolic and hormonal disorders which can lead to permanent damage such that normal growth and reproductive ability of the plants are severely hindered. On the other hand, accumulation of nanoparticles in the plant cells can be transferred from plants to higher level consumers through food chain causing severe lethal effects on non-tolerant species.

\section{References}

1. Saha N, Gupta SD (2015) Synthesis, characterization and bioactivity of nanoparticles from medicinal plants. In: Pathak M, Govil JN, Recent Progress in Medicinal Plants, Studium Press, USA, pp. 471-501.

2. Saha N, Gupta DS (2016) Biogenic synthesis and structural characterization of polyshaped gold nanoparticles using leaf extract of Swertiachirata along with process optimization by response surface methodology (RSM). J Clust Sci 27(4): 1419-1437.

3. Saha N, Trivedi P, Gupta SD (2016) Surface plasmon resonance (SPR) based optimization of biosynthesis of silver nanoparticles from rhizome extract of Curculigo orchioides Gaertn and its antioxidant potential. JClust Sci 27(6): 1893-1912.

4. Saha N, Dutta Gupta S (2017) Low-dose toxicity of biogenic silver nanoparticles fabricated by Swertiachirata on root tips and flower buds of Allium cepa. J Hazard Mater 330: 18-28.

5. Kumari M, Mukherjee A, Chandrasekaran N (2009) Genotoxicity of silver nanoparticles in Allium cepa. Sci Total Environ 407(19): 52435246.

6. Patlolla AK, Berry A, May L, Tchounwou PB (2012) Genotoxicity of silver nanoparticles in Viciafaba: a pilot study on the environmental monitoring of nanoparticles. Int J Environ Res Public Health 9(5): 1649-1662.

7. Rajeshwari A, Kavitha S, Alex SA, Kumar D, Mukherjee A, et al. (2015) Cytotoxicity of aluminum oxidenanoparticles on Allium cepa root tip effects of oxidative stress generation and bio uptake. Environ Sci Pollut Res Int 22(14): 11057-11066.

8. Kumar D, Rajeshwari A, Jadon PS, Chaudhuri G, Mukherjee A, et al. (2015) Cytogenetic studies of chromium (III) oxidenanoparticles on Allium cepa root tip cells. J Environ Sci (China) 38: 150-157.

9. Ghosh M, Bandyopadhyay M, Mukherjee A (2010) Genotoxicity of titanium dioxide $\left(\mathrm{TiO}_{2}\right)$ nanoparticles at two trophic levels: plant and human lymphocytes. Chemosphere 81(10): 1253-1262.

10. Prakash P, Gnanaprakasam P, Emmanuel R, Arokiyaraj S, Saravanan M (2013) Green synthesis of silver nanoparticles from leaf extract of Mimusopselengi Linn. for enhanced antibacterial activity against multi drug resistant clinicalisolates. Colloids Surf B Biointerfaces 108: 255259.

11. Sukirtha R, Priyanka KM, Antony JJ, Kamalakkannan S, Thangam R, et al. (2012) Cytotoxic effect of green synthesized silver nanoparticles using Melia azedarach against in vitro HeLa cell lines and lymphoma mice model. Process Biochem 47: 273-279.

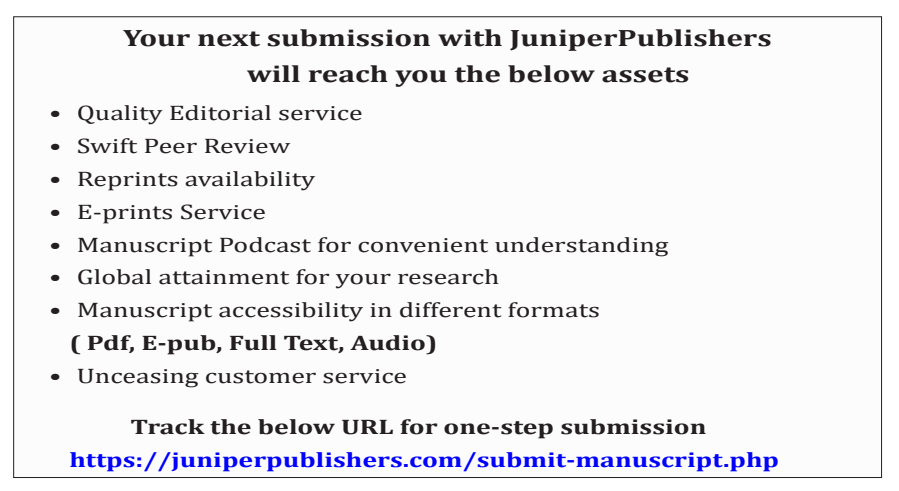

